\title{
Pengaruh Kepuasan Kerja Dan Komitmen Organisasi Terhadap Turnover Intentions Karyawan (Survey Pada PT. Telesindo Shop Cabang Pekanbaru)
}

\author{
ADI RAHMAT \\ Jurusan Manajemen Fakultas Ekonomi \\ Universitas Lancang Kuning \\ Jln. Yos Sudarso KM. 08 Rumbai-Pekanbaru \\ E-mail: a_rahmat0786@yahoo.com
}

\begin{abstract}
This research was conducted at PT. Telesindo Shop Branch Pekanbaru. The purpose of the study to determine the effect of job satisfaction and organizational commitment on employee turnover intentions PT. Telesindo shop pekanbaru branch. To achieve these objectives the research conducted by using the sample of 41 people, using census method. Methods of data analysis using descriptive and quantitative. Based on the test results bedasarkan job satisfaction variables (X1) using SPSS acquired $t_{\text {hitung }}-3.082$. So $=5 \%$, which is equal to $2.028 \alpha$ when compared to the significant $t_{\text {tabel }}$ can be seen that large $t_{\text {hitung }}$ lebih of $t_{\text {table }}(-3.082>2.028)$, thus it can be concluded that the variables X1 or negatively affects job satisfaction and turnover intentions significant to the employees of PT. Telesindo shop Pekanbaru branch. Based on the results of tests on X2 (organizational commitment) obtained $\mathrm{t}_{\text {hitung }}$ sebesar -4,131dengan comparison with $\mathrm{t}_{\text {tabel }} 2.028$ (attachment), it can be seen that $\mathrm{t}$ count $>t_{\text {table }}(-4.131>2.028)$. Thus it can be concluded that the variable $X \neg 2$ (organizational commitment) partially have a strong relationship in influencing turnove rintentions employees of PT. Telesindo shop Pekanbaru branch. Thus we can conclude that organizational commitment variable partially has a strong influence in affecting turnove rintentions employees of PT. Telesindo shop Pekanbaru branch. Recommendations can be submitted is at. Telesindo shop Pekanbaru branch, in order to further enhance the variable job satisfaction and work environment in which respondents on indicators of employee relations affect the performance of the employees received a low response of respondents with low responder on these indicators will affect employees in improving their performance.
\end{abstract}

Keywords: Job Satisfaction, Organizational Commitment and Performance turnover intention

Perhatian di bidang sumber daya manusia tidaklah boleh diabaikan karena pada bidang tersebut merupakan langkah awal dalam merencanakan tenaga kerja untuk menciptakan sumber daya yang berkualitas. Sumber daya manusia dengan akal pikirannya dapat mengelola dan mengendalikan dirinya sendiri, ia juga dapat mengelola dan mengendalikan faktor-faktor produksi yang lain yaitu dana, bahan baku, metode dan mesin. Hal ini menunjukkan bahwa sumber daya manusia dalam suatu perusahaan memegang peranan penting dalam meningkatkan kemajuan dan kelangsungan hidup organisasi.

Dalam perusahaan sumber daya manusianya adalah karyawan. Dalam hal ini, karyawan wajib dan terikat untuk mengerjakan pekerjaan yang diberikan pimpinan. Dari penjelasan tersebut dapat disimpulkan jika karyawan mempunyai kewajiban memberikan tenaga serta pikirannya untuk kepentingan perusahaan. Semua karyawan di perusahaan wajib mengembangkan potensinya sesuai dengan tujuan perusahaan. Karyawan merupakan aset utama bagi perusahaan karena tanpa adanya karyawan aktivitas perusahaan tidak akan terjadi. Karyawan berperan aktif dalam menetapkan rencana, sistem, proses, dan tujuan yang ingin dicapai perusahaan. Karyawan wajib dan terikat untuk mengerjakan pekerjaan yang diberikan dan berhak memperoleh kompensasi sesuai 
dengan perjanjian.

Setiap perusahaan dituntut untuk mengelola sumber daya manusia dengan harapan berorientasi pada penggunaan sumber daya yang efektif dan efisien. Sumber daya manusia yang handal yang dimiliki oleh perusahaan memberikan keuntungan tersendiri. Hal ini dapat terlihat apabila sumber daya manusia tersebut mampu melaksanakan berbagai tugas sesuai dengan job description. Semua sumber daya manusia wajib untuk mengembangkan potensinya sesuai dengan kebutuhan perusahaan.

Namun seringkali dalam perusahaan ada karyawan yang tidak mengerahkan seluruh kemampuan yang dimiliki untuk mencapai tujuan perusahaan karena adanya keinginan untuk pindah ke perusahaan lain. Hal ini menyebabkan tingkat turnover intentions (keluar masuknya) karyawan dalam lingkungan operasional perusahaan sering terjadi. Turnover intentions merupakan kejadian yang seringkali terdapat di perusahaan. Seperti halnya perekrutan karyawan yang terus berjalan, baik perekrutan karena faktor produktivitas karyawan yang telah menurun disebabkan faktor umur maupun perekrutan karyawan karena faktor pengunduran diri. Penggantian karyawan yang mengalami produktivitas menurun karena faktor umur dapat diantisipasi oleh perusahaan dengan menyiapkan kader-kader muda potensial untuk menggantikan.

Pengaruh yang ditimbulkan dari adanya turnover tersebut akan mempengaruhi berbagai aktivitas kerja yang terdapat pada perusahaan dan dapat juga mempengaruhi prestasi kerja karyawan secara keseluruhan. Secara nyata pengaruh yang ditimbulkan oleh adanya turnover intentions adalah perusahaan harus mengeluarkan biaya lagi dalam merekrut karyawan baru untuk menggantikan karyawan yang meninggalkan perusahaan. Pengaruh yang juga ditimbulkan adalah kesinambungan operasional perusahaan terancam karena dimungkinkan karyawan yang keluar kerja tidak mempunyai wakil yang dapat menggantikan posisinya dan posisi yang ditinggalkan masih menunggu karyawan baru.

Kepuasan kerja pada tingkat tertentu dapat mencegah karyawan untuk mencari pekerjaan diperusahaan lain. Apabila karyawan di perusahaan tersebut mendapatkan kepuasan, karyawan cenderung akan bertahan pada perusahaan walaupun tidak semua aspek-aspek yang mempengaruhi kepuasan kerja terpenuhi. Karyawan yang memperoleh kepuasan dari perusahaannya akan memiliki rasa keterikatan atau komitmen lebih besar terhadap perusahaan dibanding karyawan yang tidak puas. Berikut ini disajikan data tentang keluar masuknya karyawan di PT. Telesindo Shop cabang pekanbaru

Tabel 1: Data Tentang Keluar Masuknya Karyawan di PT. Telesindo Shop cabang pekanbaru Tahun 2010-2014

\begin{tabular}{|c|c|c|c|c|}
\hline Tahun & $\begin{array}{c}\text { Jumlah } \\
\text { karyawan } \\
\text { awal }\end{array}$ & $\begin{array}{c}\text { Jumlah } \\
\text { karyawan } \\
\text { yang keluar }\end{array}$ & $\begin{array}{c}\text { Jumlah } \\
\text { karyawan } \\
\text { yang masuk }\end{array}$ & $\begin{array}{c}\text { Jumlah } \\
\text { karyawan } \\
\text { Akhir }\end{array}$ \\
\hline 2010 & 35 & 3 & 1 & 32 \\
\hline 2011 & 32 & 2 & 4 & 34 \\
\hline 2012 & 34 & 3 & 5 & 36 \\
\hline 2013 & 36 & 2 & 4 & 38 \\
\hline 2014 & 38 & 3 & 6 & 41 \\
\hline
\end{tabular}

Sumber: PT. Telesindo shop

Kepuasan kerja pada tingkat tertentu dapat mencegah karyawan untuk mencari pekerjaan diperusahaan lain. Apabila karyawan di perusahaan tersebut mendapatkan kepuasan, karyawan cenderung akan bertahan pada perusahaan walaupun tidak semua aspek-aspek yang mempengaruhi kepuasan kerja terpenuhi. Karyawan yang memperoleh kepuasan dari perusahaannya akan memiliki rasa keterikatan atau komitmen lebih besar terhadap perusahaan dibanding karyawan yang tidak puas. Dengan demikian para ahli memberikan beberapa definisi tentang kepuasan kerja.

Menurut Robbins (2001:179) menyatakan bahwa "Kepuasan kerja sebagai suatu sikap umum seorang individu terhadap pekerjaannya". Menurut Handoko (2000:193) menyatakan bahwa kepuasan kerja (job satisfaction) adalah keadaan emosional yang menyenangkan atau tidak 
menyenangkan dengan mana karyawan memandang pekerjaan mereka. Pendapat tersebut dapat dipahami bahwa karyawan harus ditempatkan pada pekerjaan yang sesuai dengan kemampuan dan latar belakang ketrampilannya. Menurut Davis (2002:105) menyatakan bahwa " kepuasan kerja merupakan seperangkat perasaan pegawai tentang menyenangkan atau tidak menyenangkan pekerjaan mereka". Jadi kepuasan kerja mengandung arti yang sangat penting, baik dari sisi pekerja maupun perusahaan serta bagi masyarakat secara umum. Oleh karena itu maka menciptakan keadaan yang bernilai positif dalam lingkungan kerja suatu perusahaan mutlak merupakan kewajiban dari setiap jajaran pimpinan perusahaan yang bersangkutan.

Menurut Herzberg (2000:107)

mengembangkan teori kepuasan yang disebut teori dua faktor yaitu faktor yang tidak merasa puas (dissatisfier) dan faktor orang yang merasa puas (sasstisfier) artinya ketidak puasan dan kepuasan bukan merupakan variabel yang kontinyu. Penelitian awal Herzberg menghasilkan dua kesimpulan khusus mengenai teori tersebut yaitu:

1. Kondisi ekstrinsik, keadaan pekerjaan (job confext) yang menghasilakn ketidak puasan dikalangan karyawan jika kondisi tersebut tidak ada, jika kondisi tersebut ada maka tidak perlu memotivasi karyawan.

2. Kondisi Instrinsik, isi pekerjaan (job contact) yang apabila ada dalam pekerjaan tersebut akan menggerakkan tingkat motivasi yang kuat, yang dapat menghasilkan prestasi kerja yang baik. Jika kondisi tersebut tidak ada maka tidak akan menimbulakn rasa ketidak puasan yang berlebihan.

Teori ini didasarkan pada hasil penelitian dimana ia membagi situasi yang mempengaruhi sikap seseorang terhadap pekerjaannya menjadi dua kelompok yaitu:

1. Kelompok bukan pemuas (dissatisfier) merupakan faktor-faktor yang tidak adanya kepuasan yang terdiri dari upah, jaminan pekerjaan, kondisi kerja, status, prosedur pekerjaan, mutu supervisi, mutu hubungan antar pribadi diantara rekan kerja, dengan atasan dan dengan bawahan.

2. Kelompok pemuas (sastisfier) merupakan faktor-faktor yang meliputi prestasi (achievement), pengakuan (recognition), tanggung jawab (responsibility), kemajuan (advancement), pekerjaan itu sendiri (the work it self) dan kemungkinan berkembang (the possibility of growth). Indikator yang mempengaruhi kepuasan kerja menurut Hasibuan (2005:203) sebagai berikut:

a. Balas jasa yang adil dan layak

b. Penempatan yang tepat sesuai keahlian

c. Berat ringannya pekerjaan

d. Suasana dan lingkungan pekerjaan

e. Peralatan yang menunjang pelaksanaan pekerjaan

f. Sikap pimpinan dalam kepemimpinannya

g. Sifat pekerjaan monoton atau tidak

Robbins dan Judge (2007) mendefinisikan komitmen sebagai suatu keadaan dimana seorang individu memihak organisasi serta tujuan-tujuan dan keinginannya untuk mempertahankan keangotaannya dalam organisasi. Sedangkan Mathis dan Jackson (dalam Sopiah, 155) mendefinisikan komitmen organisasional sebagai derajad dimana karyawan percaya dan mau menerima tujuan-tujuan organisasi dan akan tetap tinggal atau tidak akan meninggalkan organisasinya).

Richard M. Steers (Sri Kuntjoro, 2002) mendefinisikan komitmen organisasi sebagai rasa identifikasi (kepercayaan terhadap nilai-nilai organisasi), keterlibatan (kesediaan untuk berusaha sebaik mungkin demi kepentingan organisasi) dan loyalitas (keinginan untuk tetap menjadi anggota organisasi yang bersangkutan) yang dinyatakan oleh seorang pegawai terhadap organisasinya. Steers berpendapat bahwa komitmen organisasi merupakan kondisi dimana pegawai sangat tertarik terhadap tujuan, nilai-nilai, dan sasaran organisasinya. 
Komitmen terhadap organisasi artinya lebih dari sekedar keanggotaan formal, karena meliputi sikap menyukai organisasi dan kesediaan untuk mengusahakan tingkat upaya yang tinggi bagi kepentingan organisasi demi pencapaian tujuan.

Komitmen terhadap organisasi artinya lebih dari sekedar keanggotaan formal, karena meliputi sikap menyukai organisasi dan kesediaan untuk mengusahakan tingkat upaya yang tinggi bagi kepentingan organisasi demi pencapaian tujuan. Berdasarkan definisi ini, dalam komitmen organisasi tercakup unsur loyalitas terhadap organisasi, keterlibatan dalam pekerjaan, dan identifikasi terhadap nilai-nilai dan tujuan organisasi.

Rendahnya komitmen mencerminkan kurangnya tanggung jawab seseorang dalam menjalankan tugasnya. Mempersoalkan komitmen sama dengan mempersoalkan tanggung jawab, dengan demikian, ukuran komitmen seorang pimpinan yang dalam hal ini adalah kepala sekolah adalah terkait dengan pendelegasian wewenang (empowerment). Dalam konsep ini pimpinan dihadapkan pada komitmen untuk mempercayakan tugas dan tanggung jawab ke bawahan. Sebaliknya, bawahan perlu memiliki komitmen untuk meningkatkan kompetensi diri.

Mowday yang dikutip Sopiah (2008) menyakan ada tiga aspek komitmen antara lain:

1. Affective commitment, yang berkaitan dengan adanya keinginan untuk terikat pada organisasi. Individu menetap dalam organisasi karena keinginan sendiri. Kunci dari komitmen ini adalah want to

2. Continuance commitment, adalah suatu komitmen yang didasarkan akan kebutuhan rasional. Dengan kata lain, komitmen ini terbentuk atas dasar untung rugi, dipertimbangkan atas apa yang harus dikorbankan bila akan menetap pada suatu organisasi. Kunci dari komitmen ini adalah kebutuhan untuk bertahan (need to)

3. Normative Commitment, adalah komitmen yang didasarkan pada norma yang ada dalam diri karyawan, berisi keyakinan individu akan tanggung jawab terhadap organisasi. Ia merasa harus bertahan karena loyalitas. Kunci dari komitmen ini adalah kewajiban untuk bertahan dalam organisasi (ought to).

Menurut Zeffane dikutip oleh Kurniasari (2004:20). Arti Intention adalah niat atau keinginan yang timbul pada individu untuk melakukan sesuatu. Sementara turnover adalah berhentinya seseorang karyawan dari tempatnya bekerja secara sukarela dapat didefinisikan bahwa turnover intention adalah kecenderungan atau niat karyawan untuk berhenti bekerja dari pekerjaannya secara sukarela menurut pilihannya sendiri.

Model konseptual dan model empiris tentang turnover intention memberikan dukungan kuat terhadap proporsi yang menyatakan bahwa intensi perilaku membentuk determinan paling penting dari perilaku sebenarnya (actual behavior) (Lee, Mowday, O' Really dan Cadwell, dikutip dari Kuarniasari, 2004:19). Sementara itu menurut Steel dalam Kurniasari (2004:21), penelitian mengenai proses turnover intention sebaiknya dimulai ketika karyawan baru mulai bekerja atau menjadi anggota organisasi.

Menurut Griffet dan home (1995) dalam Agung Triharso (2012:11) bahwa Hampir semua model intention to leave dikarenakan oleh tingkat kepuasan kerja dan komitmen organisasi yang rendah, yaitu:

1. Kepuasan kerja adalah sikap yang paling berpengaruh terhadap intention to leave. Hasil studi menunjukkan bahwa kepuasan kerja berkaitan erat dengan proses kognisi menarik diri (pre withdrawal cognition), intensi untuk pergi dan tindakan nyata berupa keputusan untuk keluar dari tempat kerja.

2. Komitmen organisasi adalah faktor yang paling berpengaruh terhadap terjadinya intention to leave dibanding kepuasan kerja. 
Mobley et al (1986) dalam Rodly pengumpulan data yaitu :

(2012) menyatakan bahwa banyak faktor yang menyebabkan karyawan berpindah dari tempat kerjanya namun faktor determinan keinginan berpindah diantaranya adalah:

1. Kepuasan Kerja

2. Komitmen organisasi

Menurut Harnoto (2002:2): “Turnover intentions ditandai oleh berbagai hal yang menyangkut perilaku karyawan, antara lain: absensi yang meningkat, mulai malas kerja, naiknya keberanian untuk melanggar tata tertib kerja, keberanian untuk menentang atau protes kepada atasan, maupun keseriusan untuk menyelesaikan semua tanggung jawab karyawan yang sangat berbeda dari biasanya." Model yang digunakan di dalam penelitian adalah sebagai berikut:

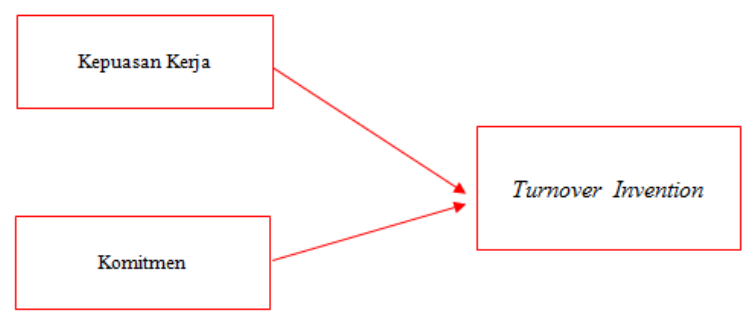

Gambar 1. Model Penelitian

Hipotesis dalam penelitian ini adalah sebagai berikut:

Ho $=$ Tidak terdapat pengaruh kepuasan kerja dan komitmen terhadap turnover invention.

$\mathrm{Ha}=$ Terdapat pengaruh kepuasan kerja dan komitmen terhadap turnover invention.

\section{METODE}

Penelitian dilakukan dengan mengPopulasi untuk penelitian ini berjumlah 38 orang. Untuk menentukan ukuran sampel dari suatu populasi, terdapat bermacam-macam cara yang dikemukakan para ahli. Pengambilan sampel dilakukan dengan teknik sampel jenuh, hal ini dilakukan karena jumlah anggota populasi relatif kecil. Jumlah sampel dalam penelitian ini sebanyak 41 orang sesuai dengan jumlah populasi.

Untuk memperoleh data dalam penelitian ini dipergunakan teknik a. Teknik pengumpulan data kepustakaan. Teknik ini digunakan untuk mengumpulkan data mengenai teoriteori, konsep-konsep yang behubungan dengan variabel penelitian dari bukubuku dan literature yang relevan.

b. Teknik Pengumpulan Data Lapangan. Teknik ini digunakan untuk menemukan data empirik dengan menggunakan angket/ kuesioner dengan Skala Likert. Menurut Kinnear (1988) yang dikutip dalam buku Metodologi Penelitian untuk Skripsi dan Tesis Bisnis (Husein Umar, 2008:70-71), Skala Likert ini berhubungan dengan pernyataan tentang sikap seseorang terhadap sesuatu. Responden diminta mengisi pernyataan dalam skala ordinal. Skala pengukuran adalah Skala Likert yang dibagi kedalam lima, pengukuran, dimana skala pengukurannya menggunakan skala 1 sampai dengan 5 (skala likert). Dimana angka 1 mewakili Sangat Tidak Setuju (STS) sampai dengan angka mewakili Sangat Setuju (SS).

Pada penelitian ini metode yang digunakan adalah dengan menggunakan analisis regresi linier berganda. Adapun rumus regresi linier berganda :

$Y=\alpha+\beta_{1} X_{1}+\beta_{2} X_{2}$

Keterangan :

$\mathrm{X}_{1}$ : Kepuasan kerja

$\mathrm{X}_{2}$ : Komitmen

$\mathrm{Y}$ : Turnover Invention

\section{HASIL}

Tabel 2. Output SPSS Model Summary Variabel kepuasan kerja, komitmen dan terhadap turnover invention.

Model
\begin{tabular}{|l|l|r|r|r|}
\hline R & R Square & $\begin{array}{c}\text { Adjusted R } \\
\text { Square }\end{array}$ & $\begin{array}{r}\text { Std. Error of } \\
\text { the Estimate }\end{array}$ \\
\hline 1 & $.744^{\mathrm{a}}$ & .554 & .531 & 1.884 \\
\hline
\end{tabular}
$\begin{aligned} & \text { a. Predictors: (Constant), Komitmen organisasi, Kepuasan } \\
& \text { kerja }\end{aligned}$

Sumber : Data primer, Olahan SPSS

Dari tabel Model Summary dapat di- 
(Survey Pada PT. Telesindo Shop Cabang Pekanbaru) (Adi Rahmat)

lihat nilai $\mathrm{R}$ Square menunjukan variabel kepuasan kerja, komitmen dan berpengaruh terhadap turnover invention sebesar 55,4\%, sedangkan sisanya sebesar $44,6 \%$ dipengaruhi oleh variabel/ faktor di luar penelitian. Dimana nilai $\mathrm{R}=0,744$ artinya merupakan nilai kontribusi yang kuat dari variabel kepuasan kerja, komitmen dan terhadap turnover invention yaitu sebesar $74 \%$.

Tabel 3. Output SPSS Anova Variabel kepuasan kerja, komitmen dan terhadap turnover invention.

ANOVA $^{b}$

\begin{tabular}{|c|c|c|c|c|c|c|}
\hline \multicolumn{2}{|c|}{ Model } & $\begin{array}{l}\text { Sum of } \\
\text { Squares }\end{array}$ & df & Mean Square & $F$ & Sig. \\
\hline \multirow[t]{3}{*}{1} & Regression & 167.561 & 2 & 83.781 & 23.604 & $.000^{\circ}$ \\
\hline & Residual & 134.878 & 38 & 3.549 & & \\
\hline & Total & 302.439 & 40 & & & \\
\hline
\end{tabular}

a. Predictors: (Constant), Komitmen organisasi, Kepuasan Kerja b. Dependent Variable: Tumover intentions

Sumber : Data primer, Olahan SPSS

Uji $F$ dilakukan untuk mengetahui hubungan secara serentak, dari hasil output SPSS pada tabel 3 dapat dilihat nilai signifikan variabel kepuasan kerja, komitmen dan terhadap turnover invention secara simultan menunjukan nilai sig. $0,000(<0,05)$ pada tingkat $\alpha=5 \%$. Hal ini menunjukan bahwa terdapat pengaruh yang signifikan antara variabel kepuasan kerja, komitmen dan terhadap turnover invention.

Tabel 4. Output SPSS Coefficients Variabel kepuasan kerja, komitmen dan terhadap turnover invention.

Coefficients $^{a}$

\begin{tabular}{|c|c|c|c|c|c|c|}
\hline \multirow[b]{2}{*}{ Model } & & \multicolumn{2}{|c|}{ Unstandardized Coefficients } & \multirow{2}{*}{$\begin{array}{c}\begin{array}{c}\text { Standardized } \\
\text { Coefficients }\end{array} \\
\text { Beta }\end{array}$} & \multirow[b]{2}{*}{$t$} & \multirow[b]{2}{*}{ Sig. } \\
\hline & & $B$ & Std Error & & & \\
\hline \multirow[t]{3}{*}{1} & (Constant) & 52.809 & 2.440 & & 21.643 & .000 \\
\hline & Kepuasan keria & .208 & .067 & .373 & .3082 & .004 \\
\hline & Komitmen organisasi & .336 & .081 & .500 & -4.131 & .000 \\
\hline
\end{tabular}

Sumber : Data primer, Olahan SPSS

Pada tabel coefficients variabel kepuasan kerja, komitmen dan terhadap turnover invention, terlihat:

a. Variabel kepuasan kerja terhadap turnover invention dengan nilai signifikannya adalah sig. 0,004. Nilai sig. $0,004<0,05$, di mana menunjukkan pengaruh yang signifikan antara kepuasan kerja terhadap turnover invention.

b. Variabel komitmen terhadap turnover invention dengan nilai signifikannya adalah sig. 0,000. Nilai sig. 0,000<0,05, di mana menunjukkan pengaruh yang signifikan antara komitmen terhadap turnover invention.

Dari tabel 4 dapat juga dilihat bahwa konstanta $(\alpha)$ sebesar 52,809, koefisien $\beta_{1}$ sebesar -0,208, koefisien $\beta_{2}$ sebesar $-0,336$. sehingga dapat ditampilkan ke dalam bentuk persamaan :

$Y=\alpha+\beta_{1} X_{1}+\beta_{2} X_{2}$

Jika diasumsikan dapat ditulis persamaan sebagai berikut:

$\mathrm{Y}=52,809-0,208 \mathrm{X}_{1}-0,336 \mathrm{X}_{2}$

Dari persamaan di atas dapat diartikan bahwa:

1. Besarnya pengaruh kepuasan kerja $\left(X_{1}\right)$ terhadap turnover invention sebesar 0,208, ini berarti apabila variabel kepuasan kerja ditingkatkan sebesar satu satuan variabel, maka turnover invention akan menurun sebesar 0,208 kali satuan variabel, dengan syarat variabel $\mathrm{X}_{2}$ tetap, dan apabila variabel kepuasan kerja dimisalkan nol (tetap), maka variabel turnover invention tetap ada sebesar konstanta $-0,208$.

2. Besarnya pengaruh komitmen $\left(\mathrm{X}_{2}\right)$ terhadap turnover invention sebesar 0,336, ini berarti apabila variabel komitmen ditingkatkan sebesar satu satuan variabel, maka turnover invention akan menurun sebesar 0,336 kali satuan variabel, dengan syarat variabel $\mathrm{X}_{1}$ tetap, dan apabila variabel komitmen dimisalkan nol (tetap), maka variabel turnover invention tetap ada sebesar konstanta $-0,336$.

\section{PEMBAHASAN}

Berdasarkan hasil penelitian yang menunjukkan adanya pengaruh yang 
signifikan antara variabel-variabel kepuasan tinggi. Mereka yang kepuasan kerjanya kerja, komitmen dan terhadap turnover rendah lebih mudah meninggalkan invention. Maka dapat dibuat pembahasan dari hasil penelitian tersebut,

Hasil pengolahan pengolahan data ini menunjukkan terdapat hubungan antara kepuasan kerja dengan turnover intention. Hal ini sejalan dengan hasil penelitian yang dilakukan oleh Yohana dan Sherly (2008), yang dilakukan menunjukkan turnover intentions berpengaruh secara signifikan terhadap kepuasan kerja karyawan. Tingkat turnover intentions 3 karyawan cenderung rendah, karena rata-rata karyawan cukup puas dan bahkan puas dengan pekerjaannya. Selain itu berdasarkan penelitian yang dilakukan oleh Sunjoyo dan Harsono (2003) dalam Palupi (2011), di Kantor Akuntan Publik di Bandung, Surabaya, dan Jakarta yang fokus penelitiannya adalah faktor-faktor yang mempengaruhi turnover intentions menunjukkan bahwa hanya faktor kepuasan kerja saya yang mempengaruhi turnover intentions sementara ketiga dimensi dalam komitmen organisasi yang terdiri dari afektif, continuance, dan normatif tidak menunjukkan pengaruh yang signifikan.

Dari hasil ini menunjukkan bahwa hubungan antara kepuasan kerja dengan turnover intention berbanding terbalik artinya semakin tinggi kepuasan kerja karyawan maka akan semakin rendah pula turnover intention dan juga sebaliknya semakin rendah kepuasan kerja maka akan diikuti pula semakin tingginya turnover intention karyawan. Mathis dan Jackson (2001) mengidentifikasi bahwa masuk-keluar (turnover) tenaga kerja berhubungan dengan ketidakpuasan kerja. Semakin tinggi tingkat kepuasan kerja seseorang, maka semakin rendah intensitasnya untuk meninggalkan pekerjaannya itu, hal ini dibuktikan pada penelitian Lum et al., (1998); Johson (1987); Yuyetta (2002) dan Tett \& Meyer (1993) Handoko (1998); Lum et al., (1998), menyatakan bahwa kepuasan kerja berpengaruh terhadap perputaran karyawan, kepuasan kerja yang rendah biasanya mengakibatkan perputaran karyawan yang perusahaan lain. Selain itu juga Hullin et.al perusahaan lain. Selain itu juga Hullin et.al (1985) mengakui bahwa alternatif pekerjaan dan kepuasan kerja dapat memiliki pengaruh yang substansial pada keinginan keluar pekerja pada berbagai populasi. Ketidakpuasan kerja telah sering diidentifikasikan sebagai suatu alasan yang penting yang menyebabkan individu meninggalkan pekerjaannya.

Faktor-faktor yang mempengaruhi kepuasan kerja menurut Effendy (2000:92) sebagai berikut:

a. Upah yang cukup

Upah yang cukup untuk kebutuhan merupakan keinginan setiap karyawan. Untuk tercapainya hal tersebut ada diantara para karyawan yang menggiatkan diri dalam bekerja atau menambah pengetahuannya dengan mengikuti kursus.

b. Perlakuan yang adil

Setiap karyawan ingin diperlakukan secara adil, tidak saja dalam hubungannya dengan upah, tetapi juga dalam hal-hal lain, untuk dapat menciptakan persepsi yang sama antara atasan dengan bawahan mengenai makna adil yang sesungguhnya, maka perlu diadakan komunikasi yang terbuka antara mereka.

c. Ketenangan bekerja

Setiap karyawan menginginkan ketenangan, bukan saja hubungannya dengan pekerjaan, tetapi juga menyangkut kesejahteraan keluarganya.

d. Perasaan diakui

Pada setiap karyawan terdapt perasaan ingin diakui sebagai karyawan yang berharga dan sebagai anggota kelompok yang dihormati. Hal ini berhubungan dengan kegiatan-kegiatan diluar tugas pekerjaan, seperti: olah raga, kesenian dan lain-lain.

e. Penghargaan atas hasil kerja

Para karyawan menginginkan agar hasil karyanya dihargai, hal ini bertujuan agar 
karyawan merasa senang dalam bekerja Intention) merupakan sinyal awal terjadinya dan akan selalu bekerja dengan segiatgiatnya.

f. Penyalur perasaan

Perasaan tertentu yang menghinggapi para karyawan bisa menghambat gairah kerja. Hal ini dapat diatasi melalui komunikasi dua arah secara timbal balik.

Pendapat lain dikemukakan oleh Ghiselli dan Brown (2003:110) mengemukakan faktor-faktor yang mempengaruhi kepuasan kerja karywan adalah:

a. Kedudukan

b. Pangkat/golongan

c. Jaminan Keuangan dan sosial

d. mutu pengawasan kerja yang dijalankan Komitmen organisasional didefinisikan sebagai suatu keadaan dimana seorang karyawan memihak organisasi tertentu serta tujuan-tujuan dan keinginannya untuk mempertahankan keanggotaan dalam organisasi tersebut. Jadi, keterlibatan pekerjaan yang tinggi berarti memihak pada pekerjaan tertentu seorang individu, sementara komitmen organisasional yang tinggi berarti memihak organisasi yang merekrut individu tersebut. Keadaan ini sangat baik bagi pencapaian tujuan organisasi karena organisasi mendapat dukungan penuh dari anggotanya sehingga dapat berkonsentrasi secara penuh pada tujan yang diprioritaskan. Morrison (1997) dalam dalam Hersusdadikawati (2004), menyatakan bahwa komitmen merupakan faktor yang penting bagi organisasi karena: (1) pengaruhnya bagi turnover dan (2) hubungannya dengan kinerja yang mengasumsikan bahwa individu yang mempunyai komitmen cenderung mengembangkan upaya yang lebih besar pada pekerjaan. Johnson et al (1990) dalam Hersusdadikawati (2004), mengatakan bahwa komitmen organisasi berhubungan negatif terhadap keinginan untuk pindah, semakin tinggi komitmen organisasinya maka semakin rendah keinginannya untuk pindah dari tempat kerjanya semakin kecil begitu juga sebaliknya.

Keinginan untuk pindah (Turnover

turnover karyawan di dalam organisasi. Turnover Intention adalah derajat kecenderungan sikap yang dimiliki oleh karyawan untuk mencari pekerjaan baru di tempat lain atau adanya rencana untuk meninggalkan perusahaan dalam masa tiga bulan yang akan datang, enam bulan yang akan datang, satu tahun yang akan datang dan dua tahun yang akan datang, Low et al (2001) dalam Widodo (2010). Sikap lain yang secara simultan muncul dalam individu ketika muncul turnover intention adalah berupa pikiran untuk keluar, keinginan untuk mencari lowongan pekerjaan lain, mengevaluasi kemungkinan untuk menemukan pekerjaan yang lebih baik di tempat lain. Namun demikian apabila kesempatan untuk pindah kerja tersebut tidak tersedia atau yang tersedia tidak lebih menarik dari yang sekarang dimiliki, maka secara emosional dan mental karyawan akan keluar dari perusahaan yaitu dengan sering datang terlambat, sering bolos, kurang antusias atau kurang memiliki keinginan untuk berusaha dengan baik, Russ dan McNeilly (1995) dalam Widodo (2010).

Menurut Suwandi dan Nur Indriantoro, turnover dapat dibedakan menjadi dua jenis, yaitu:

1. Voluntary turnover: karyawan meninggalkan perusahaan karena alasan sukarela. Voluntary turnover dapat dibedakan menjadi dua:

a. Avoidable turnover (yang dapat dihindari)

avoidable turnover (yang dapat dihindari) disebabkan oleh : upah yang lebih balk di tempat lain, kondisi kerja yang lebih balk di organisasi lain, masalah dengan kepemimpinan/administrasi yang ada, serta adanya organisasi lain yang lebih baik

b. Unavoidable turnover (yang tidak dapat dihindari)

unavoidable turnover (yang tidak dapat dihindari) disebabkan oleh : pindah kerja ke daerah lain karena 
mengikuti pasangan, perubahan arah karir individu, harus tinggal di rumah untuk menjaga pasangan atau anak, dan kehamilan.

2. Involuntary turnover: karyawan meninggalkan perusahaan karena terpaksa. Involuntary turnover diakibatkan oleh tindakan pendisiplinan yang dilakukan oleh perusahaan atau karena lay off.

\section{SIMPULAN}

Berdasarkan hasil penelitian dan pembahasan serta analisis yang telah dilakukan maka penulis akan menarik kesimpulan dari hasil penelitian mengenai pengaruh kepuasan kerja dan komitmen organisasi terhadap turnover intentions karyawan PT. Telesindo Shop Cabang Pekanbaru.

1. Dapat diketahui bahwa pengaruh kepuasan kerja dan komitmen organisasi mempengaruhi turnover intentions karyawan PT. Telesindo Shop Cabang Pekanbaru dengan memperoleh rata-rata tanggapan positif sebesar 3,52 ini berarti bahwa kinerja perusahaan dalam kategori setuju.

2. Hasil penelitian pada R. Square sebesar $0,554(55,4 \%)$ ini menerangkan bahwa turnover intentions karyawan PT. Telesindo Shop Cabang Pekanbaru dapat diterangkan oleh faktor kepuasan kerja dan komitmen organisasi, berpengaruh sebesar $55,4 \%$. sedangkan sisanya sebesar $44.9 \%$ menggambarkan variabel bebas lainnya yang tidak diamati dalam penelitian ini

3. Bedasarkan hasil pengujian pada variabel kepuasan kerja $\left(\mathrm{X}_{1}\right)$ dengan menggunakan bantuan SPSS diperoleh $\mathrm{t}_{\text {hitung }}$ sebesar $-3,082$. Maka bila dibandingkan pada $t_{\text {tabel }}$ pada signifikan $\alpha$ $=5 \%$, yakni sebesar 2,028 dapat dilihat bahwa $t_{\text {hitung }}$ lebih besar dari $t_{\text {tabel }}(-3,082$ $>$ 2,028), dengan demikian dapat disimpulkan bahwa variabel $X_{1}$ atau kepuasan kerja mempengaruhi negatif dan signifikan terhadap turnover intentions karyawan PT. Telesindo Shop Cabang Pekanbaru.

4. Bedasarkan hasil pengujian pada variabel $\mathrm{X}_{2} \quad$ (komitmen organisasi) diperoleh $t_{\text {hitung }}$ sebesar -4,131 dengan perbandingan dengan $t_{\text {tabel }}$ sebesar 2.028 (lampiran), dapat terlihat bahwa $t_{\text {hitung }}>$ $t_{\text {tabel }}(-4,131>2,028)$. Dengan demikian maka dapat disimpulkan bahwa variabel $\mathrm{X}_{2}$ (komitmen organisasi) secara parsial memiliki hubungan yang kuat dalam mempengaruhi turnover intentions karyawan PT. Telesindo Shop Cabang Pekanbaru.

Dari kesimpulan penelitian diatas, maka penulis dapat memberikan masukan sebagai berikut:

1. Diharapkan kepada PT. Telesindo Shop Cabang Pekanbaru dapat memperhatikan mengenai kepuasan kerja karyawan karena ini dapat mempengaruhi turnover intentions karyawan. Dimana perusahaan harus memperhatikan gaji yang di terima karyawan, peralatan dan ruangan kerja, kondisi kerja dan memperhatikan sikap atasan kepada bawahannya.

Pada PT. Telesindo Shop Cabang Pekanbaru, agar lebih meningkatkan lagi pada variabel komitmen organisasi dimana dari tanggapan responden pada variabel ini mendapat tanggapan tinggi dengan tingginya tanggapan responden pada pernyataan ini akan mempengaruhi meningkatnya turnover karyawan PT. Telesindo Shop Cabang Pekanbaru. Ini dapat ditingkatkan dengan perusahaan memperhatikan tingkat usia karyawan, tingkat pendidikan karyawan, ruang lingkup jabatan, mengakomodir terjadinya konflik dan tingkat pengendalian yang dilakukan pimpinan.

\section{DAFTAR RUJUKAN}

As'ad, Moh. 2004. Psikologi Industri: Seri Sumber Daya Manusia. Edisi Ketiga. Penerbit Liberty. Yogyakarta

Rivai, Veithzal dan Sagala, Jauvani. 2009. Manajemen Sumber Daya Manusia 
212 Pengaruh Kepuasan Kerja Dan Komitmen Organisasi Terhadap Turnover Intentions Karyawan (Survey Pada PT. Telesindo Shop Cabang Pekanbaru) (Adi Rahmat)

Untuk Perusahaan. Jakarta: Rajawali Press

Robbins, Stephen P. 2003. Perilaku organisasi. Jakarta: PT. Index Group Gramedia.

Santoso, Singgih. 2002. Buku Latihan SPSS: Statistik Parametrik. Cetakan Ketiga. Jakarta: PT. Elex Media Komputindo

Siagian, Sondang. 2004. Manajemen Personalia. Cetakan Ketiga. Bumi Aksara. Jakarta

Sugiyono. 2002. Statistika Untuk Penelitian. Alfa Beta:Bandung

Sunjoyo \& Harsono. 2003. Pengaruh kepuasan kerja dan komitmen organisasional terhadap turnover intention. Program Studi Manajemen: Program Pascasarjana Universitas Gadjah Mada.

Frizal Fariz. 2006."Pengaruh Komitmen Organizational Dan Kepuasan Kerja Terhadap Turnover Intention Para Marketing Pada PT. Loka Wisata Asridi Surabaya". Skripsi sarjana tidak diterbitkan, STIE PerbanasSurabaya.

Wulansari, Yohana dan Sunardi Sherly.2008.Analisa pengaruh kepuasan kerjakaryawan terhadap turnover intention di PT Sentra Media Kominika Surabaya. Program Studi Manajemen: Universitas Kristen Petra

Azwar Saifuddin. 2005. "Reliabilitas dan Validitas". Edisi 2, Yogyakarta : Pustaka Pelajar.

Cameli Abraham. 2004. "The Relationship Between Work Commitment Models And Employee Withdrawal Intention". Journal of Business Management (Oktober) pp 63-84.

Indiantoro dan Suwandi, 2004. "Pengujian Model Turnover Intention Pada Akuntan Publik". Journal Riset Akuntansi Universitas Gajah Mada.

Mohammad Abdullah Hamdi, Aizzat Mohd. Nasurdin. 2006. "Predicting Turnover Intentions Of Hotel Employee. The Influence Of Employee Development Human
Resource Management Practices And Trust In Organization", Gadjah Mada Internasional Journal of Business, January-April 2006, vol.8, no.1, pp.21-42.

Abelson, M. A. 1987. Examination of Avoidable and Unavoidable Turnover.Journal of Allied Phsychology.

Arianto, A. T. 2001, Analisis FaktorFaktor yangMempengaruhi Turnover Intention Pada staff KantorAkuntan Publik.Jurnal Akuntansi dan Keuangan.

Meyer dan Tett. 1993.Job Satisfaction, OrganizationalCommitment,

Turnover Intention and Turnover.Personnel Psychology.

Rivai, H.A. 2001.Pengaruh Kepuasan Gaji, Kepuasan Kerjadan Komitmen Organisasional terhadap IntensiKeluar.Jurnal Bisnis dan Akuntansi.

Suhanto, E. 2009.Pengaruh Stres Kerja dan Iklim Organisasi terhadap TurnoverIntention dengan Kepuasan Kerjasebagai Variabel Intervening. Tesis Program Pasca sarjana Magister Manajemen Universitas Diponegoro.Semarang.

Ferdinand, Augusty. 2010. "Structural Equation Modeling dalam Penelitian Manajemen: Aplikasi Model-model Rumit dalam Penelitian untuk Tesis Magister dan Disertasi Doktor". ISBN 979-9156-75-0. UNDIP Semarang.

Fornell, C. dan Larcker, D.F. 1981. Evaluating Structural Equation Models with Unobservable Variables and Measurement Error. Journal of Marketing Research, 18, 39-50

Gibson, James,L. 2000. Organisasi, Perilaku, Struktur dan Proses. Edisi ke-5. Cetakan ke-3. Jakarta: Penerbit Erlangga.

Grant, K., D.W. Cravens, G.S. Low dan W.C. Moncrief. (2001). The Roleo of Satisfaction with Territory 
Design on The Motivation, Attitudes, Handoko, T. Hani. 2001. Manajemen and Work Outcomes os Sales People. Journal of The Academy of Marketing Science, Vol. 29, No.2, pp.165-178. Personalia dan Sumber Daya Manusia. Edisi ke 14. Yogyakarta : BPFE

Ghozali, Imam. 2011. Aplikasi Analisis Multivariate dengan Program IBM SPSS 19. Semarang: Universitas Diponegoro.

Hackett, R.D., Bycio, and P.A. Hausdorf. 1994. Further Asesstments of Meyer and Allens. 1991. Three component model Organizational Commitment. Journal of Applied Psychology, Vol. 79, No.4, Februari, pp.15-23.

Hadi, Sutrisno. 2004. Metodologi Research. Jilid 3. Yogyakarta: Andi Offset.

Wijaya, Elsa Fricha. 2010. "Pengaruh Job Insecurity, Komitmen Karyawan dan Kepuasan Kerja terhadap Intention to Quit (Studi pada PT. Bank Jatim Cabang Malang)". Tesis: Program Magister Manajemen Minat Manajemen SDM. Pascasarjana Fakultas Ekonomi Universitas Brawijaya Malang.

Witasari, Lia. (2011). "Analisis Pengaruh Kepuasan Kerja dan Komitmen Organisational terhadap Turnover Intentions (Studi Empiris pada Novotel Semarang)". Fakultas Ekonomi UNDIP Semarang.

Harris, G. E, \& Cameron J. E. 2005. Multiple dimensions of organizational identification and commitment aspredictors of turnover intentions and psychological well-being. Canadian Journal of Behavioural Science, 37 (3), 159-169. http://dx.doi.org/ 10.1037/h0087253

Judge, T.A., \& Welbourne, T.M 1994. A Confirmatory Investigation of Dimensionality of Pay Satisfaction Questionnaire. Journal of Applied Phsychology. 79(1); 461-466.

Kuncoro, Mudrajad. 2003. Metode Riset untuk Bisnis dan Ekonomi. Jakarta: Erlangga.

Layne, C; Hohenshil, T; Singh, K. 2004. The Relationship of Occupational Stres, Psychological Strain, and Coping Resources to the Turnover Intentions of Rehabilitation Counselors. Rehabilitation Counseling Bulletin, V 01.48, No.1,pp. 19-26. 